\title{
P16INK4A Expression on Retinoblastoma at Mohammad Hoesin Hospital Palembang
} Sri Tanty Fuji A Harahap ${ }^{1 *}$, Ika Kartika ${ }^{1 *}$, Rusdianto ${ }^{1 *}$

${ }^{1}$ Department of Ophthalmology, Faculty of Medicine, Universitas Sriwijaya, Indonesia *Correspondence author email: sritantyfuji@gmail.com

\begin{abstract}
Background: Retinoblastoma is a malignant tumor with an average incidence of one case per 15,00020,000 births. Retinoblastoma is associated with the presence of the $\mathrm{Rb} 1$ gene mutation which has role in preventing DNA replication. Various studies have linked the existence of $\mathrm{p} 16^{\mathrm{INK} 4 \mathrm{~A}}$ as a CDK inhibitor that inhibits Cyclin D and CDK4 so that the activity of the Rb1 gene is inhibited.

Methods: A descriptive study used on the paraffin blocks of 14 cases Retinoblastoma in Mohammad Hoesin Hospital Palembang from January 2014- July2018. Histopathologic feature were examined with Hematoxylin- Eosin staining and immunohistochemical were examined with p16 ${ }^{\mathrm{INK} 4 \mathrm{~A}}$ antibody. Data were analyzed using SPSS version23 to identify histopathological feature of $\mathrm{p} 16^{\mathrm{INK} 4 \mathrm{~A}}$ expression in Retinoblastoma

Results: Most retinoblastoma samples in this study were expressed in p16 ${ }^{\mathrm{INK} 4 \mathrm{~A}}(92.86 \%)$. The degree of differentiation of retinoblastoma with the largest number at Mohammad Hoesin Hospital is moderately differentiated (57.14\%). Retinoblastoma invasion of the optic nerve and sclera in the study at Mohammad Hoesin Hospital, respectively at $57.14 \%$ and $42.86 \%$.
\end{abstract}

Conclusion: Most retinoblastoma samples in this study were expressed in $\mathrm{p} 16^{\mathrm{INK} 4 \mathrm{~A}}$.

Keywords: p16 ${ }^{\mathrm{INK} 4 \mathrm{~A}}$, Retinoblastoma, moderately differentiated 


\section{Introduction}

Retinoblastoma is a primary intraocular malignant tumor derived from retinoblasts in the developing retina is a neuroblastic tumor that is similar to other types of tumors such as melanoma or metastasis and progressive that can be used in children..$^{1-4}$ Retinoblastoma is a malignant tumor with an average number of 15,000-20,000 births. ${ }^{5-6}$ About $45 \%$ of retinoblastoma cases are hereditary problems, $15 \%$ are done unilaterally and $30 \%$ are bilateral and are sporadic and appear as unilateral tumors. ${ }^{6}$ Section of Hemato-Oncology of children in RSCM in the period 2010-2016 which included retinoblastoma amounted to 156 cases and this is the most severe malignancy after acute lymphocytic leukemia. ${ }^{7}$ While data from the Hemato-Oncology section of Children's Hospital Dr. Mohammad Hoesin Palembang retinoblastoma as many as 37 cases were received from $2008-2014 .^{8}$ The diagnosis begins with a clinical look at retinoblastoma such as leukocoria, which is a white pupillary reflex containing tumors, strabismus in either esotropia or exotropia and ocular inflammation used for vision. ${ }^{3}$ Ultrasound, CT scan and MRI can be used to help diagnose retinoblastoma. ${ }^{4}$ The gold standard for diagnosis of retinoblastoma is a histopathological examination known as three degrees of differentiation of retinoblastoma, which is well differentiated, moderately differentiated, and poorly differentiated. ${ }^{4}$ ${ }^{9-11}$ Retinoblastoma, whether acquired or acquired(sporadic), $\quad$ is received in the presence of a Rb1 gene mutation. This Rb1 gene mutation will cause the pRB protein to not need or even not exist at all before the protein is needed associated with tumor cell growth by preventing DNA replication. ${ }^{12}$ Research conducted at Sienna University involved $\mathrm{P} 16^{\mathrm{INK} 4 \mathrm{~A}}$ tumor suppressor protein in the pathogenesis of retinoblastoma and its role as a predisposition to familial cancer. The expression of $\mathrm{P} 16^{\mathrm{INK} 4 \mathrm{~A}}$ was analyzed in tumor samples from retinoblastoma patients with immunohistochemistry and peripheral blood examination from patients and both patients with real time quantitative-PCR (qRTPCR) reverse transcription. In this study it was found that $56 \%$ of cases that showed down regulation of P16 ${ }^{\mathrm{INK} 4 \mathrm{~A}}$ had at least one parent who carried the same alteration in his blood cells. ${ }^{13}$ Indovina et al. consider $\mathrm{P} 16^{\mathrm{INK} 4 \mathrm{~A}}$ as a marker taken against retinoblastoma. Analysis of the $\mathrm{P} 16^{\mathrm{INK} 4 \mathrm{~A}}$ promoter methylation showed hypermetilation in the majority of patients with down regulation of P16 ${ }^{\mathrm{INK} 4 \mathrm{~A}}$ and in parents of patients with the same alteration on reflecting P16 ${ }^{\mathrm{INK} 4 \mathrm{~A}}$. Indovina et al. Completed in his research that down regulation of $\mathrm{P} 16^{\mathrm{INK} 4 \mathrm{~A}}$ occurred in $55 \%$ of retinoblastoma patients. ${ }^{14}$ Research byLiu et al. at the Zhongshan Ophthalmic Center for 65 cases of retinoblastoma during the 2008- 2010 period, 


\section{ज5्चण}

\section{SRIWIJAYA \\ JOURNAL OFOPHTHALMOLOGY}

determining which shows high $\mathrm{P} 16^{\mathrm{INK} 4 \mathrm{~A}}$ is associated with a decrease in the level of differentiation of retinoblastoma. The expression of $\mathrm{P} 16^{\mathrm{INK} 4 \mathrm{~A}}$ also requires a risk of a poor prognosis so that $\mathrm{P} 16^{\mathrm{INK} 4 \mathrm{~A}}$ can be a marker of a fairly good prognosis for retinoblastoma. ${ }^{15}$ Morbidity and mortality are quite high in retinoblastoma and data related to $\mathrm{P} 16^{\mathrm{INK} 4 \mathrm{~A}}$ in retinoblastoma in Indonesia does not yet exist, so this study was conducted to support $\mathrm{P} 16^{\mathrm{INK} 4 \mathrm{~A}}$ in retinoblastoma and responded with $\mathrm{P} 16^{\mathrm{INK} 4 \mathrm{~A}}$ response to differences in histopathological differentiation of retinoblastoma in Dr. Hospital. Mohammad Hoesin Palembang.

\section{Methods}

This research is a descriptive study that aims to determine the description of $\mathrm{P} 16^{\mathrm{INK} 4 \mathrm{~A}}$ expression by immunohistochemical examination on retinoblastoma tissue samples at Dr. General Hospital Mohammad Hoesin Palembang. The research was conducted at the Eye Polyclinic and Anatomy Pathology Laboratory of Dr. General Hospital Mohammad Hoesin Palembang. The implementation time is from March 2018 to December 2018. The target population is all retinoblastoma patients seeking treatment at the Eye Clinic at Dr. General Hospital Mohammad Hoesin Palembang who had and will be undergoing surgical removal of retinoblastoma tumors from January 2012 to July 2018. The research subjects were retinoblastoma patients who came to the Eye Polyclinic of Dr. General Hospital. Mohammad Hoesin Palembang, who had histopathological preparations of retinoblastoma (paraffin block) from January 2012 to July 2018 who met the inclusion criteria and signed an agreement for patients for the period March 2018 to July 2018. The inclusion criteria were (a) Preparations derived from surgery that contain retinoblastoma tumor tissue at the General Hospital Dr. Mohammad Hoesin Palembang. (b) Histopathological preparations in good condition or appropriate for immunohistochemical examination. (c) Willing to follow the stated research by signing an informed consent (for new cases / primary data). The exclusion criteria were (a) Histopathological preparations obtained as a result of retinoblastoma but in an improper condition (dry paraffin block) for immunohistochemical examination (b) Histopathological preparations obtained retinoblastoma results but in the amount of tissue is not enough to do immunohistochemical (IHC) examination. Sampling is done by total sampling technique. Suspected retinoblastoma patients who met the inclusion criteria were given informed consent, ophthalmological examination and support. The 
research data was collected in a research form and then arranged in the form of a master table. The data obtained will be presented in the form of tables and graphs and then narrated. Data were analyzed using SPSS version 23 to identify histopathological features of P16 ${ }^{\mathrm{INK} 4 \mathrm{~A}}$ expression in retinoblastoma.

\section{Results}

General characteristics of research subjects include age and gender. Based on sex, the incidence of retinoblastoma in this study obtained as much as $64.29 \%$ of the male and female samples as much as $35.71 \%$. In this study, the majority of subjects aged $0-3$ years amounted to $64.29 \%$ and above 3 years amounted to $35.71 \%$. The average age of retinoblastoma patients in this study was

2.93 years with the youngest age affected by retinoblastoma is 2 months and the oldest age affected by retinoblastoma was 8 years. Details of the general characteristics of the research subjects are explained in the following table.

Table 1. General characteristics of research subjects

\begin{tabular}{lcc}
\hline General characteristics & $\mathbf{n}$ & \% \\
\hline Sex & & \\
Male & 9 & $64 . .29$ \\
Female & 5 & 35.71 \\
\hline Age & & \\
$\leq 3$ years & 9 & 64.29 \\
$>3$ years & 5 & 35.71 \\
\hline Total & $\mathbf{1 4}$ & $\mathbf{1 0 0}$ \\
\hline
\end{tabular}

In terms of tumor lateralization, retinoblastoma generally occurs unilateral. In this study, $92.86 \%$ of the samples were unilateral retinoblastoma and $7.14 \%$ were classified as bilateral retinoblastoma. In this study, the histopathological features of the sample were assessed consisting of the degree of differentiation and invasion. Tablel 2 presents data on the degree of differentiation 
of retinoblastoma which is classified as well, moderately, poorly differentiated and undifferentiated. Retinoblastoma sample at Dr. General Hospital Mohammad Hoesin Palembang showed a differentiated histopathology differentiation of $57.14 \%$, followed by a poorly differentiated histopathology differentiation of $21.43 \%$, well differentiated histopathology differentiation of $14.29 \%$, and undifferentiated histopathological differentiation of $7.14 \%$. In this study, as many as 8 Retinoblastoma samples were found, invading the optic nerve (57.14\%). As many as $21.43 \%$ or 3 samples showed no invasion of the optic nerve and 3 samples $(21.43 \%)$ invasion was difficult to determine.

Table 2. Histopathological description

\begin{tabular}{lcr}
\hline Differentiation & $\mathbf{n}$ & $\mathbf{\%}$ \\
\hline Well Differentiated & 2 & $14 . .29$ \\
Moderately Differentiated & 8 & 57.14 \\
Poorly Differentiated & 3 & 21.43 \\
Undifferentiated & 1 & 7.14 \\
\hline
\end{tabular}

\section{Invasion of the Optical Nervus}

\begin{tabular}{lcc}
\hline Positive & 8 & 57.14 \\
\hline Negative & 3 & 2143 \\
\hline Difficult to Determine & 3 & 21.43 \\
\hline Invasion of Sclera / Choroid & & \\
\hline Positive & 6 & 42.86 \\
\hline Negative & & \\
\hline Total & 8 & 57.14 \\
\hline
\end{tabular}


In this study the results obtained as many as 6 samples Retinoblastoma there is an invasion of the optic nerve $(42.86 \%)$. A total of $57.14 \%$ or 8 samples also showed no invasion of the optic nerve. The results of this study showed positive P16 ${ }^{\mathrm{INK} 4 \mathrm{~A}}$ expression in 13 samples $(92.86 \%)$ and 1 sample with negative $\mathrm{P} 16^{\mathrm{INK} 4 \mathrm{~A}}$ expression $(7.14 \%)$. Based on table 3 in this study, the positive P16 ${ }^{\mathrm{INK} 4 \mathrm{~A}}$ expression results are classified based on differentiation, which is well differentiated by 1 sample from a total of 13 samples $(7.14 \%)$, moderately differentiated by 8 samples $(57.14 \%)$, poorly differentiated by 3 samples $(21.43 \%)$, and undifferentiated in 1 sample $(7.14 \%)$. In this study also obtained negative P16 ${ }^{\mathrm{INK} 4 \mathrm{~A}}$ expression results which all include the degree of well differentiated. The result of coloring is categorized only into three groups, namely negative, weak positive, and strong positive. In samples with positive $\mathrm{P} 16^{\mathrm{INK} 4 \mathrm{~A}}$ expression, the results obtained were 6 samples $(42.86 \%)$ weak positive staining and 7 samples $(50 \%)$ strong positive and 1 sample negative.

Table 3. Characteristics P16 ${ }^{\text {INK4A }}$ based on Retinoblastoma Histopathology Degree Differentiation and Cell Intensity and Proportion

Degree Differentiation

\section{Characteristics}

P16 INK4A
Well
Moderately
Poorly
Undifferentiated

\begin{tabular}{llllllll}
\hline $\mathrm{n}$ & $\%$ & $\mathrm{n}$ & $\%$ & $\mathrm{n}$ & $\%$ & $\mathrm{n}$ & $\%$
\end{tabular}

\begin{tabular}{cccccccccc}
\hline Positive & 1 & 7.14 & 8 & 57.14 & 3 & 21.43 & 1 & 7.14 & 13 \\
Negative & 1 & 7.14 & 0 & 0 & 0 & 0 & 0 & 0 & 1 \\
\hline
\end{tabular}

Cell Intensity and Proportion

\begin{tabular}{cccccc}
\hline \multicolumn{2}{c}{ Negative } & \multicolumn{2}{c}{ Positive Weak } & \multicolumn{2}{c}{ Positive Strong } \\
\hline n & $\%$ & n & $\%$ & n & $\%$
\end{tabular}

$\begin{array}{lccccccc}\text { Positive } & 0 & 0 & 6 & 42.86 & 7 & 50 & 13 \\ \text { Negative } & 1 & 7.14 & 0 & 0 & 0 & 0 & 1\end{array}$


Based on table 4 in this study, the results of positive P16 ${ }^{\mathrm{INK} 4 \mathrm{~A}}$ expression that invaded the optic nerve were 8 samples from a total of 14 samples totaling $57.14 \%$, which did not experience invasion as much as $14.29 \%$ and the remaining $21.43 \%$ were included in the sample with invasion of the optic nerve which is difficult to determine. All negative P16 ${ }^{\mathrm{INK} 4 \mathrm{~A}}$ expressions fall into the category of not invading the optic nerve. For negative P16 ${ }^{\mathrm{INK} 4 \mathrm{~A}}$ expressions all included in the category did not experience invasion of the choroid / sclera. For the results of the intensity and proportion of weak positive cells, $21.43 \%$ of the samples were classified as moderately differentiated and the remaining $21.43 \%$ were classified as poorly differentiated. For the results of the intensity and proportion of cells in the strong positive category, 1 sample of a total of 7 samples is classified as well differentiated, $7.14 \%$ is classified as undifferentiated and $35.71 \%$ is classified as moderately differentiated.

The characteristics of the intensity and proportion of cells based on invasion of the choroid / sclera, the results obtained for the negative category are all included in the category of not experiencing invasion of the choroid / sclera. For the weak positive category, $21.43 \%$ of samples experienced invasion of choroid / sclera and $21.43 \%$ did not experience invasion of choroid / sclera. As for the strong positive category, it was found that $21.43 \%$ experienced an invasion of choroid / sclera $28.57 \%$ had no invasion of choroid / sclera. 
Table 4. Characteristics of P16 ${ }^{\mathrm{INK} 4 \mathrm{~A}}$ based on Retinoblastoma Invasion

and degree of differentiation

Invasion of the Optical Nervus

Invasion to Choroid /

Characteristics

P16 INK4A

\begin{tabular}{lll}
\hline$(+)$ & $(-)$ & Difficult to \\
& Determine
\end{tabular}

Determine

Sclera Total (+) (-)

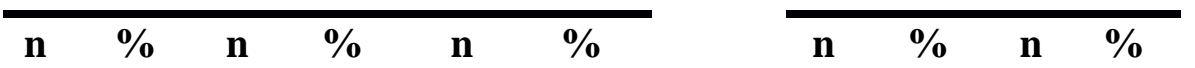

\begin{tabular}{ccccccccccccc}
\hline Positif & 8 & 57.14 & 2 & 14.29 & 3 & 21.43 & 13 & 6 & 42.86 & 7 & 50.0 & 13 \\
Negatif & 0 & 0 & 1 & 7.14 & 0 & 0 & 1 & 0 & 0 & 1 & 7.14 & 1 \\
\hline
\end{tabular}

Degree of differentiation

Well Moderately Poorly Undifferentiated

$\begin{array}{lllllllll}\text { n } & \% & \mathbf{n} & \% & \mathbf{n} & \% & \mathbf{n} & \% & \text { Total }\end{array}$

\begin{tabular}{cccccccccc}
\hline Negative & 1 & 7,14 & 0 & 0 & 0 & 0 & 0 & 0 & 1 \\
Weak Positive & 0 & 0 & 3 & 21.43 & 3 & 21.43 & 0 & 0 & 6 \\
Strong Positive & 1 & 7.14 & 5 & 35.71 & 0 & 0 & 1 & 7.14 & 7 \\
\hline
\end{tabular}

Based on table 5 which illustrates the characteristics of the intensity and proportion of cells based on invasion of the optic nerve, the results for the negative category are all included in the category of not having an invasion of the optic nerve. For the weak positive category, $28.57 \%$ of samples experienced an invasion of the optic nerve and 14.29\% did not experience an invasion of the optic nerve. As for the strong positive category, it was found that as many as $28.57 \%$ had an invasion of the optic nerve and $21.43 \%$ had an invasion of the optic nerve which was difficult to determine. 


\section{JOURNAL OF OPHTHALMOLOGY}

धत्र०

Table 5. Characteristics of P16 ${ }^{\mathrm{INK} 4 \mathrm{~A}}$ (intensity and proportion of cells) based on invasion of optic nerve and Invasion to Choroid / Sclera

Positive

Negative
Difficult to Determine

Total

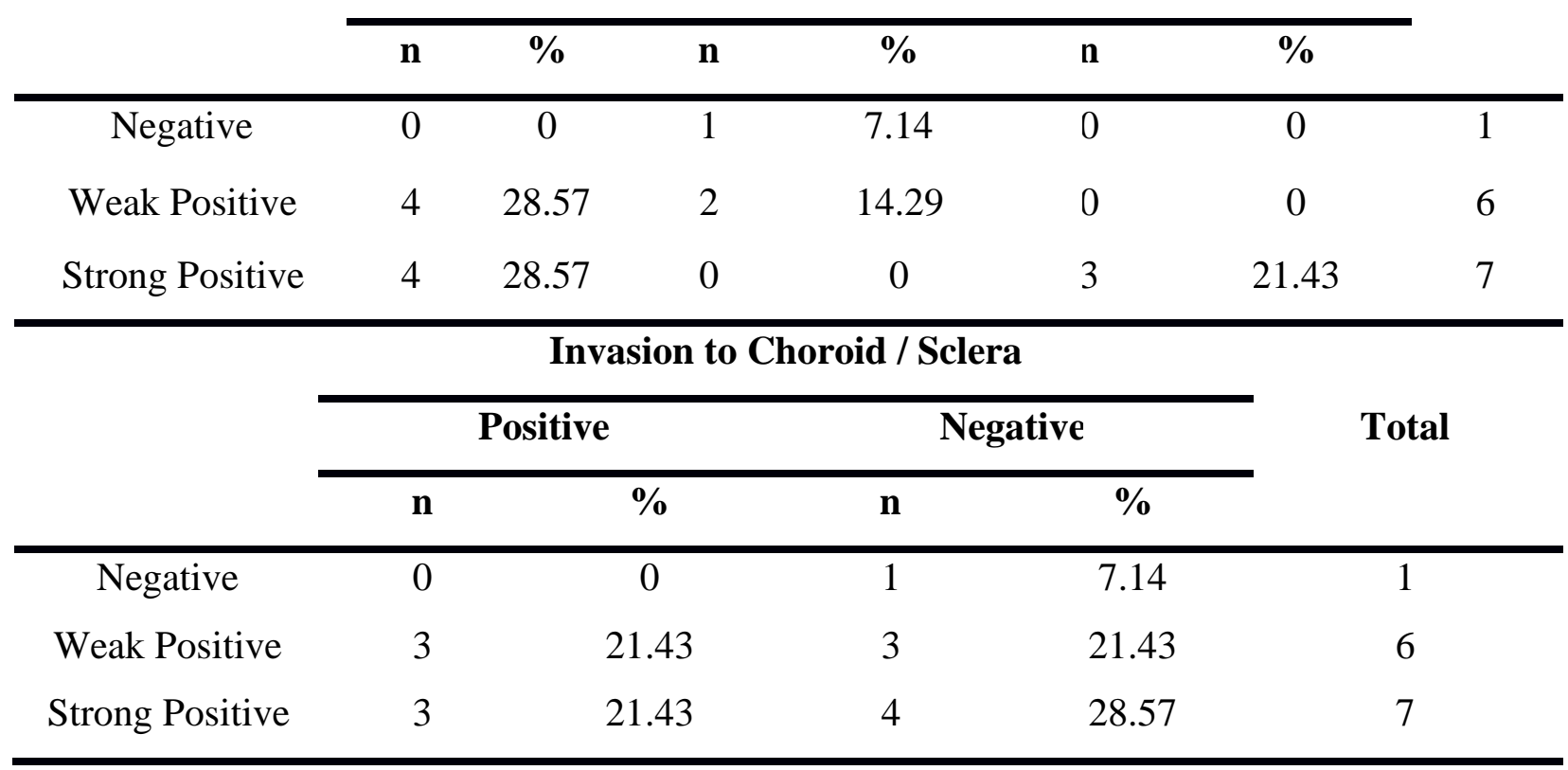

Here we present the histopathological picture of retinoblastoma and immunohistochemistry in the image below: 


\section{SRIWIJAYA JOURNAL OF OPHTHALMOLOGY}

ज्ञात
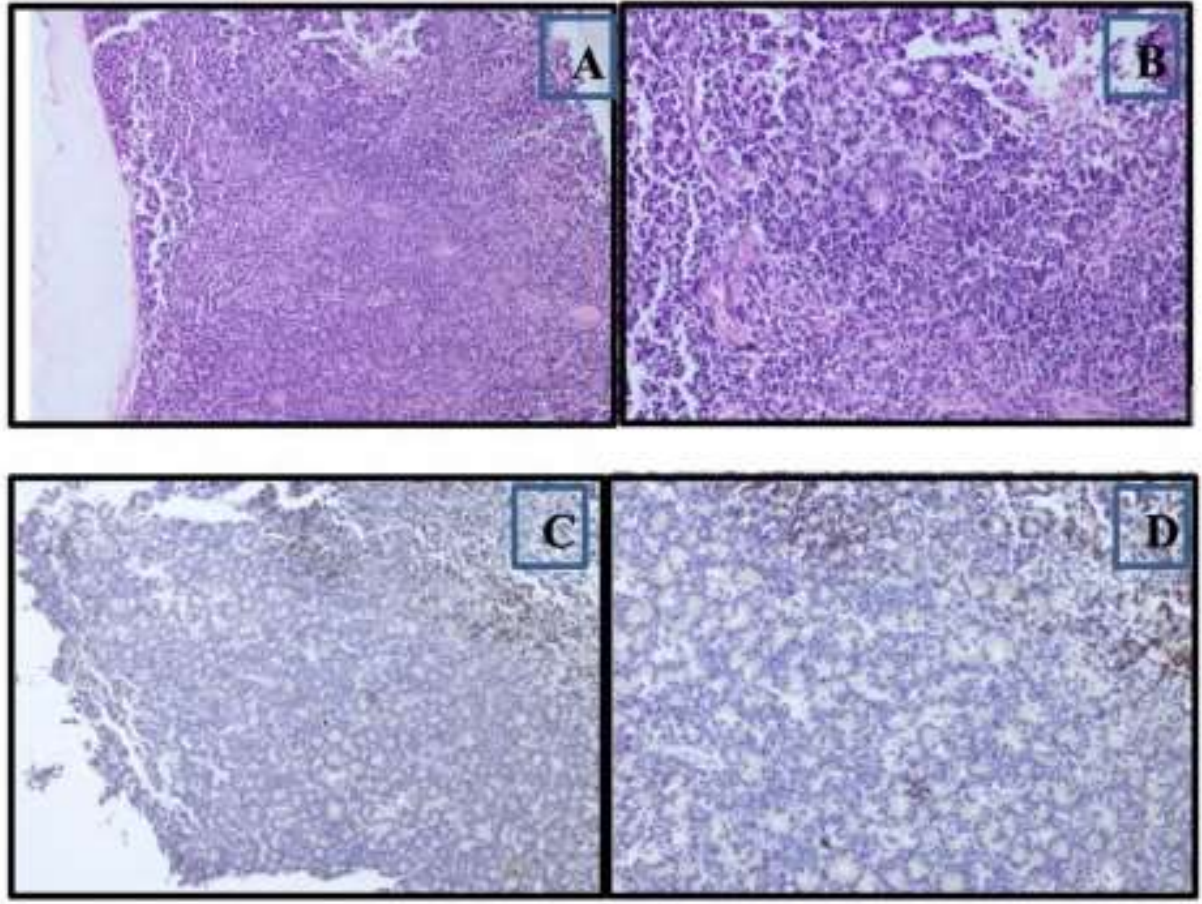

Figure 1. Results of Histopathology and Immunohistochemistry A. Sample Histopathology Examination No. 4 (Well-differentiated). Hematoxylin-Eosin staining, 100x magnification. B. Hematoxylin-Eosin staining, 200x magnification. C. Immunohistochemical Examination of P16 $6^{\mathrm{INK} 4 \mathrm{~A}}$ (-) expression. D. 100x magnification. Immunohistochemical Expression of P16 ${ }^{\mathrm{INK} 4 \mathrm{~A}}$ () expression. 200x magnification. 


\section{SRIWIJAYA JOURNAL OF OPHTHALMOLOGY}

\section{द्या०}
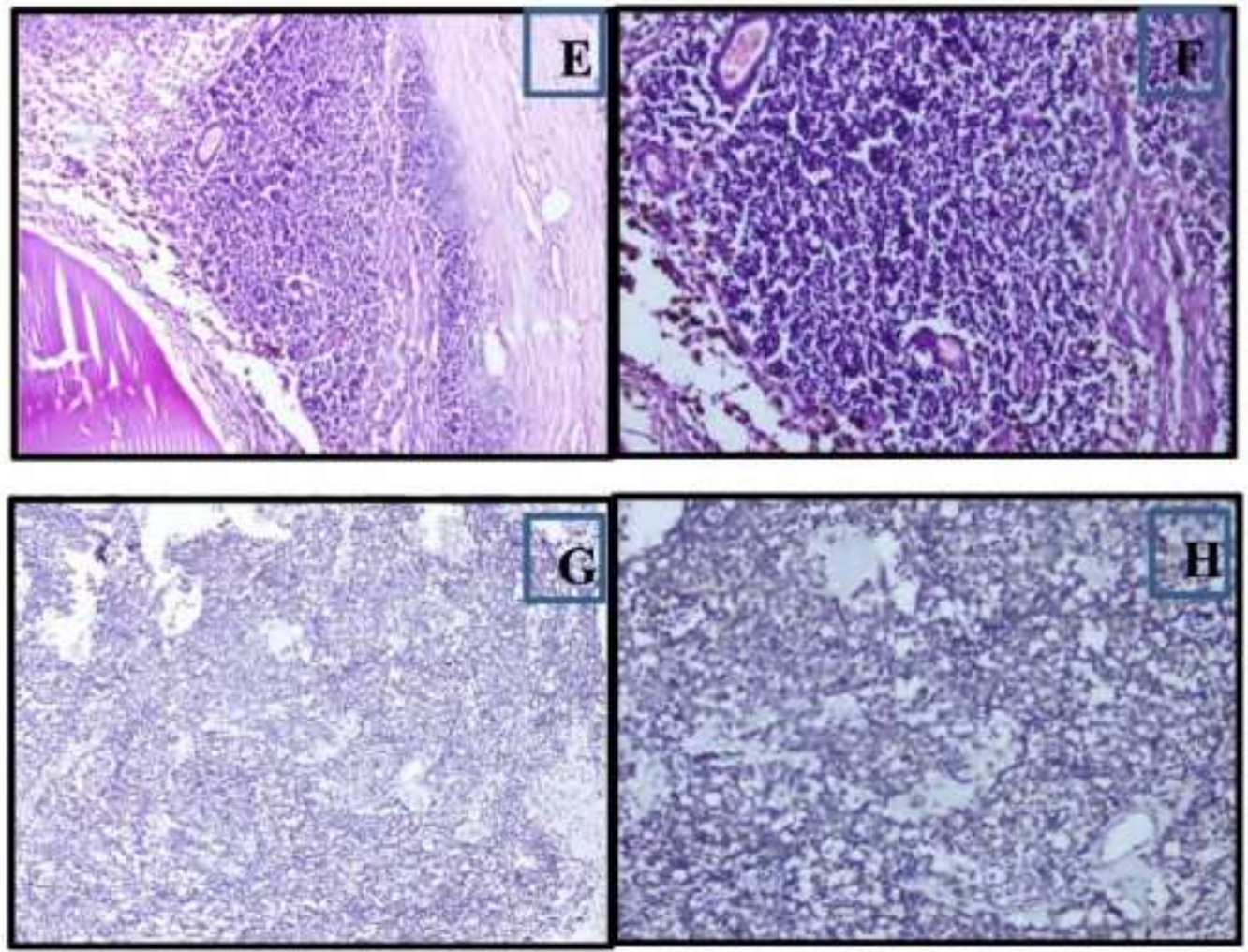

Figure 2. Results of Histopathology and Immunohistochemistry E. Sample Histopathology Examination No. 7 (Poorly Differentiated). Hematoxylin-Eosin staining, 100x magnification. F. Hematoxylin-Eosin staining, 200x magnification. G. Immunohistochemical examination Expression of $\mathrm{P} 16^{\mathrm{INK} 4 \mathrm{~A}}(+)$ with weak positive intensity. H. 100x magnification. Immunohistochemical Examination of P16 ${ }^{\mathrm{INK} 4 \mathrm{~A}}(+)$ expression with weak positive intensity. 200x magnification.

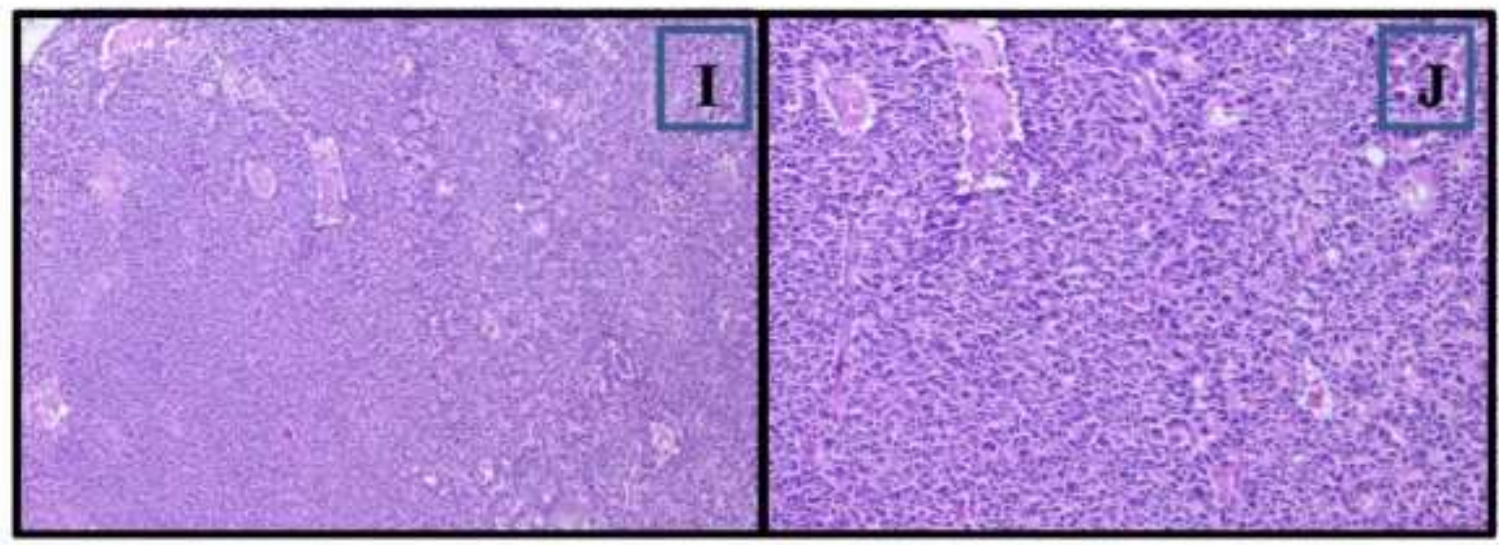




\section{SRIWIJAYA JOURNAL OFOPHTHALMOLOGY}

ज्ञा०

Figure 3. Results of Histopathology and Immunohistochemistry Examination I. Sample Histopathology Examination No. 13 (Moderately Differentiated). Hematoxylin-Eosin staining, 100x magnification. J. Hematoxylin-Eosin staining, 200x magnification.
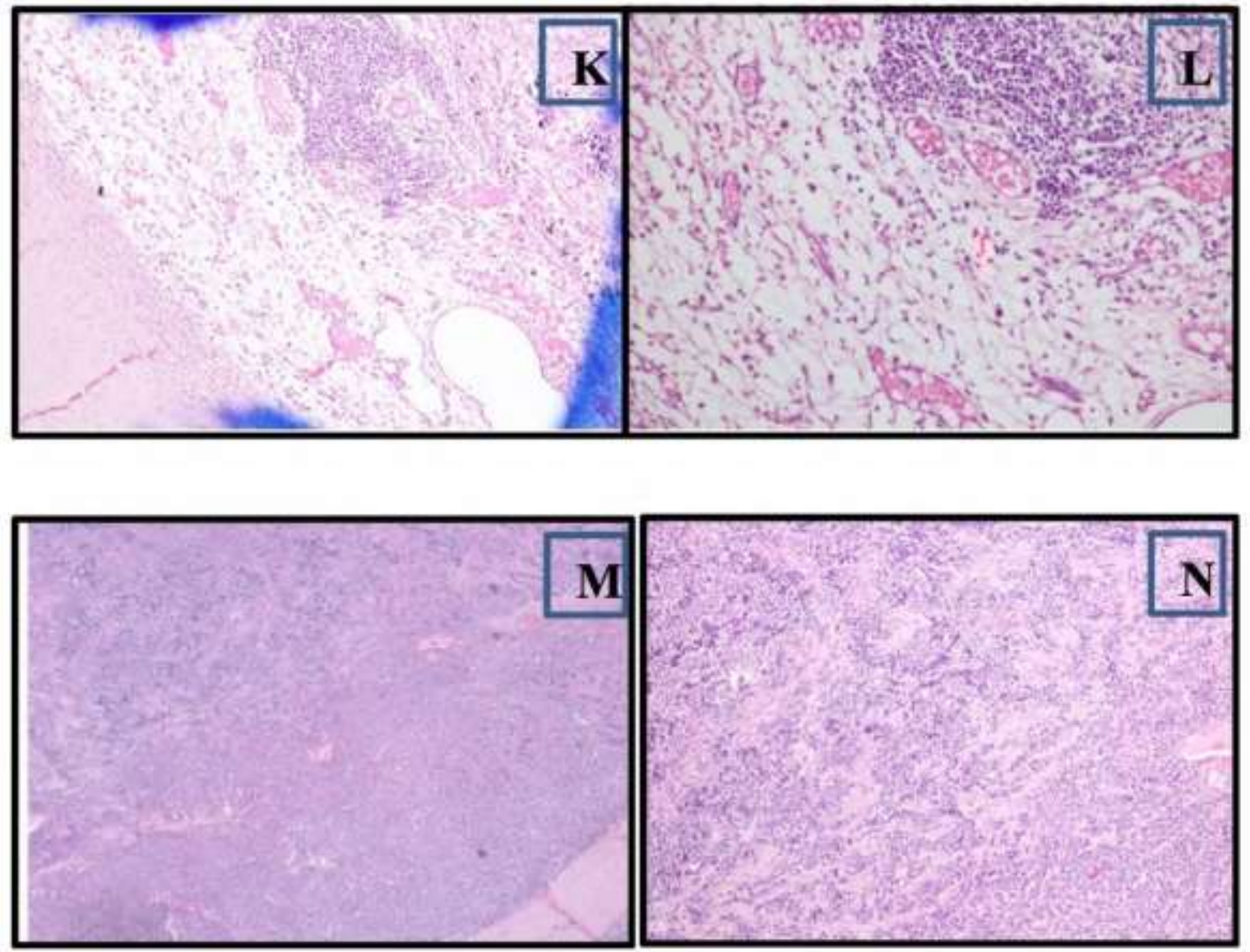

Figure 4. Results of Histopathology Examination of optic nerve invasion and sclera invasion. K. Histopathological examination of sclera invasion in sample no. 5 with Hematoxylin-Eosin Staining, 100x magnification. L. Hematoxylin-Eosin staining, 200x magnification. M. Histopathology examination of optic nerve invasion Hematoxylin-Eosin staining, enlargement 100x.N. Hematoxylin-Eosin staining, 200x magnification.

\section{Discussion}

Based on sex, the incidence of retinoblastoma in this study found $64.29 \%$ of the sample were male 
and female as much as $35.71 \%$. In a study conducted by Youssef et al. It was found that retinoblastoma occurred in $42.9 \%$ of male and female samples of $57.1 \% .{ }^{16}$ However, the American Academy of Ophthalmology reported that there was no difference in predilection between sexes in the occurrence of retinoblastoma where the incidence of retinoblastoma in the report was known to be almost similar between menand women. ${ }^{4,17}$ This is also supported by research conducted by Knudson in 48 research samples, $52.08 \%$ of male sex samples and $47.92 \%$ of female sex samples or in other words the incidence of retinoblastoma is almost similar between men and women. ${ }^{18}$ In a similar study by Mendoza it was also explained that out of a total of 266 cases of retinoblastoma, 147 cases of male retinoblastoma (55.3\%) were comparable to cases of retinoblastoma occurring in women $(44.7 \%){ }^{11}$

In this study, the majority of subjects aged 0-3 years amounted to $64.29 \%$ and above 3 years amounted to $35.71 \%$. The average age of retinoblastoma patients inthis study was 2.93 years with the youngest age affected by retinoblastoma is 2 months and the oldest age affected by retinoblastoma was 8 years. Skuta in his research explained that about $90 \%$ of cases were diagnosed in patients less than 3 years old. Aerts et al. mentioned in his research that retinoblastoma occurs in the average age of 2 years. The Union for International Cancer Control 2014 in the Review of Cancer Medicines on the WHO List of Essential Medicines states that retinoblastoma is a type of eye cancer that is usually experienced by very young children where two-thirds are diagnosed before the age of 2 years and $95 \%$ are diagnosed before age 5 year. Almost the same thing was also found in a study of 266 cases of retinoblastoma by Mendoza where usually retinoblastoma cases were found on average at the age of 2 years with details of $23.3 \%$ found at the age of less than 1 year, $34.6 \%$ at the age of 1-2 years and $42 \%$ at the age of more than two years. $^{4,11,19,20}$

In terms of tumor lateralization, retinoblastoma generally occurs unilateral. In this study, $92.86 \%$ of samples were unilateral retinoblastoma and 7.14\% were classified as bilateral retinoblastoma. Skuta in his research explained that patients with a family history of retinoblastoma were diagnosed with retinoblastoma at 4 months of age, patients with bilateral retinoblastoma would be diagnosed at 12 months of age and patients with unilateral retinoblastoma would be diagnosed at 24 months of age. RodriguezGalindo et al. explained that retinoblastoma indeed consists of two general forms, namely unilateral which occupies about $75 \%$ of total retinoblastoma cases overall and bilateral, which is about $25 \%$ of total cases. In a study conducted by Mendoza in 266 cases of retinoblastoma, it was found that around $86.8 \%$ of cases were unilateral retinoblastoma, while 35 cases, namely around $13.2 \%$, were bilateral cases. This was also 


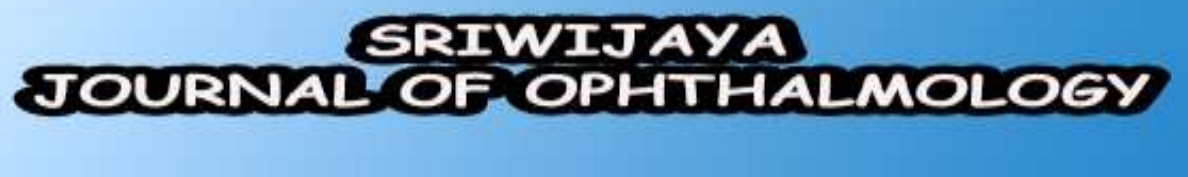

found in a study conducted by Liu et al in which 55 retinoblastoma patients were unilateral retinoblastoma cases. $^{4,11,15,21}$

In this study, paraffin preparations block retinoblastoma tissue subjects storedin the Department of Anatomical Pathology at the General Hospital Dr. Mohammad Hoesin Palembang was made in pieces as thick as 4 micrometers and then painted with $\mathrm{P} 16^{\mathrm{INK} 4 \mathrm{~A}}$ antibodies with immunohistochemical techniques. The degree of differentiation is then read under a microscope to observe various histopathological features in the sample tissue. The degree of differentiation assessment is done by observing it in four criteria, namely undifferentiated (no rosettes or fleurettes), poorly differentiated (only Homer Wright rosettes), moderately differentiated (the presence of Homer Wright and or FlexnerWintersteiner), and well differentiated (the presence of Flexner- Wintersteiner), Homer Wright and / or fleurettes). Retinoblastoma sample at Dr. General Hospital Mohammad Hoesin Palembang showed a differentiated histopathology differentiation of $57.14 \%$, followed by a poorly differentiated histopathology differentiation of $21.43 \%$, well differentiated histopathology differentiation of $14.29 \%$, and undifferentiated histopathology differentiation of $7.14 \%$. This is in accordance with research conducted by Chandrakar et al. which get $52.3 \%$ histopathology differentiation modaretely differentiated, followed by poorly differentiated histopathology differentiation of $35.7 \%$, and well differentiated histopathology differentiation of $11.9 \%$. Different things were found in a study conducted on 266 cases of retinoblastoma by Mendoza, found about 31.6\% were poorly differentiated cases, $18 \%$ were moderately differentiated cases and $10.5 \%$ were well differentiated cases. The same thing was found in the study of Owoeye et al. in a pathology study in Ilorin Nigeria diagnosed with retinoblastoma in the Ophthalmology Department of UITH, it was found that as many as 14 cases $(82.6 \%)$ were cases with poorly differentiated classification, 4 cases were classified as moderately differentiated (17.4\%) and there were no cases classified as well differentiated. ${ }^{11,21}$

Several factors can be the cause of this difference, including the age of the sample. Younger age is usually a degree of differentiation is still good or medium, while at an older age the degree of differentiation tends to be worse. Eagle et al explained that tumors in older children tend to be poorly differentiated, whereas the picture of rosettes is more clearly seen in younger children. ${ }^{24}$ In this study, reported results regarding the invasion of retinoblastoma into the optic nerve and sclera were $57.14 \%$ and $42.86 \%$, respectively. Research conducted on 266 cases of retinoblastoma by Mendoza, found about $15 \%$ of the total cases where invasion of the choroid and $18 \%$ of cases of invasion of the optic nerve. In this 


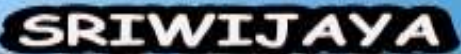 JOURNALOFOPHTHALMOLOGY}

표

study there were 3 cases whose level of invasion was difficult to determine. This difference can be caused by the optic nerve structure that is difficult to identify in histopathological preparations. ${ }^{18}$

\section{Conclusion}

Most retinoblastoma samples in this study were expressed on $\mathrm{P} 16^{\mathrm{INK} 4 \mathrm{~A}}$. The greatest amount of retinoblastoma differentiation in the Hospital of Dr. Mohammad Hoesin Palembang is at moderately differentiated degrees. The presence of retinoblastoma invasion into the optic nerve and sclera in the research at RSUP Dr. Mohammad Hoesin, respectively $57.1 \%$ and $42.9 \%$. Future studies are expected to be conducted with a larger number of samples with varying degrees of histopathology to determine the relationship of $\mathrm{P} 16^{\mathrm{INK} 4 \mathrm{~A}}$ in retinoblastoma cases. 


\section{References}

1. Pandey AN. Retinoblastoma: an Overview. Saudi journal of Ophthalmology. 2014. 28: 31015.

2. Dimaras H, Kimani K, Dimba EAO, Gransdahl P, White A, Chan HSL, Gallie BL. Retinoblastoma. Lancet. 2012. 379: 1436-46.

[3]. Tasman W, Jaeger EA. The Wills Eye Hospital Atlas of Clinical Opthalmology. $2^{\text {nd }}$ ed. Pennsylvania: Lippincolt Williams and Wilkins.

[4]. Skuta et al. Retinoblastoma. Opthalmic pathology and Intraocular Tumors. American Academy of Ophthalmology. Section 4. 2014-2015. 299-314.

[5]. Kashyap S, Sethi S, Meel R, Pushker N, Sen S, Singh M, Chandra M, Ghose S. A Histopathologic Analysis of Eyes Primarily Enucleated for Advanced Intraocular Retinoblastoma from a Developing Country. Arch Pathol Lab Med. 2012. 136: 190-3.

[6]. Kandalam M, Mitra M, Subramanian K, Biswas J. Molecular Pathology of Retinoblastoma. Middle East Afr J Opthalmol. 2010. 17(3): 217-33.

[7]. Departemen Anak Divisi Hemato- Onkologi. Data Insiden Tumor Anak. Jakarta: The Department 2010.

[8]. Data dari Bagian Hemato-Onkologi Anak Rumah Sakit Dr. Mohammad Hoesin Palembang.

[9]. Abramson, D. Retinoblastoma in the 20 ${ }^{\text {th }}$ Century: Past Success and Future Challenges. The Weisenfeld Lecture. Investigative Ophthalmology Visual Science, August 2005 Vol 6.

[10]. Shields C, Jerry A. Diagnosis and Management of Retinoblastoma. Cancer Control.2004. 115: 317-27.

[11]. Mendoza PR, Specht CS, Hubbard GB, Wells JR, Lynn MJ, Zhang Q, Grossniklaus HE. Histopathologic Grading of Anaplasia in Retinoblastoma. Am J Ophthalmol. 2015. 159(4): 764776.

[12]. Takahashi A, Ohtani N, Hara E. Irreversibility of Cellular Senescence: Dual Roles of P16 ${ }^{\text {INK4A }}$ /Rb-Pathwayin Cell Cycle Control. Cell Division. 2007. 2(10):1-5.

[13]. Acton QA. Retinoblastoma: New Insights for the Healthcare Professional. 2011.

[14]. Indovina P, Falco GD, Acquaviva A, Giordano. Downregulation and Aberrant Promoter Methylation of P16 ${ }^{\mathrm{INK} 4 \mathrm{~A}}$ : A Possible Novel Heritable Susceptibility Markerto 


\section{SRIWIJAYA JOURNAL OF OPHTHALMOLOGY}

ध50

Retinoblastoma. Journal of Cellular Physiology 2009. 223(1):143-50.

[15]. Liu Y, Zhong X, Wan S, Zhang W, Lin J, Zhang P, Li Y. P16 ${ }^{\mathrm{INK} 4 \mathrm{~A}}$ Expression in Retinoblastoma: A Marker of Differentiation Grade. Diagnostic Pathology. 2014. 9:180.

[16]. Youssef NS, Said AM. Immunohistochemical expression of CD117 and vascular endothelial growth factor in retinoblastoma: possible targets of new therapies. Int J Clin Exp Pathol. 2014. 7(9): 5725-5737

[17]. Char DH. Tumor of the Eye and Ocular Adnexa. 2001. Canada : American Cancer Society.

[18]. Knudson AG. Mutation and Cancer: Statistical Study of Retinoblastoma. PNAS. 1971. 68(4): $820-823$.

[19]. Aerts I, Rouic LL, Gauthier-Villas M, Brisse H, Doz F, Desjardins L. Retinoblastoma. Orphanet Journal of Rare Diseases. 2006. 1:31

[20]. Union for International CancerControl. Retinoblastoma. 2014 Review of Cancer Medicines on the WHO List of Essential Medicines.

https://www.who.int/selection_medici nes/committees/expert/20/applications/

Retinoblastoma.pdf.

[21]. Rodrigues KE, Latorre Mdo R, de Camargo B. Delayed Diagnosis in Retinoblastoma. J Pediatr (Rio J). 2004. 80: 511-16 (in Portuguese). 